MILITARY TECHNICAL COLLEGE CAIRO-EGYPT

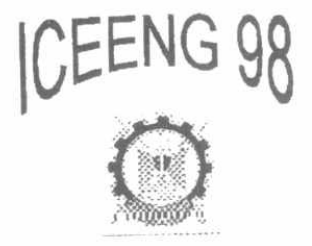

FIRST INTERNATIONAL CONF. ON ELECTRICAL ENGINEERING

\title{
COMPLEXES OF TETRAVALENT CERIUM WITH SULPHATE IONS
}

\author{
N. Hafez **, M.M.El-Dessouky *and M.S.Sayed***
}

\section{ABSTRACT :}

The sulphate - complexes of tetravalent cerium have been studied. Their stability and conditions of their formation solutions has been investigated. In addition the ease of hydrolysis of tetravalent cerium salts in sulphate solutions indicates a lower stability for the monosulphato tetravalent creium ion. The instability constants of the corresponding complexes were calculated from the results of spectrophotometric measurments. In dilute sulphate solutions of tetravalent cerium the complex cation $\left[\mathrm{C} \in \mathrm{SO}_{4}\right]^{2+}$ is predominant ; $\mathrm{K}_{\text {inst. }}=2.6 \times 10^{-3}$. When the concentration is raised to 0.05 $\mathrm{M}$ mainly the neutral complex $\mathrm{Ce}\left(\mathrm{SO}_{4}\right)_{2}$ is formed; $\mathrm{K}_{\text {inst }}=5.9 \times 10^{-3}$. In solutions coritaining an excess of sulphuric acid, cerium exists mainly as a complex anion.

\section{KEY WORDS}

Complexes, Cerium, Sulphates, Analysis.

\section{INTRODUCTION :}

The sulphate - complexes of tetravalent cerium have been described as $\left[\mathrm{CeSO}_{4}\right]^{2+}$, $\mathrm{Ce}\left(\mathrm{SO}_{4}\right)_{2},\left[\mathrm{Ce}\left(\mathrm{SO}_{4}\right)_{2}\right]^{2-}$ and $\left[\mathrm{Ce}\left(\mathrm{SO}_{4}\right)_{4}\right]^{4-}[1-6]$. The published information concerning their stability and conditions of their formation does not agree with the behaviour of cerium in sulphate solutions.

The instability constants of $\mathrm{Ce}\left(\mathrm{SO}_{4}\right)_{2}$ ion is given as $5.7 \times 10^{-4}$ and $2.8 \times 10^{-4}$ by $(3,4)$. In addition the ease of hydrolysis of tetravalent cerium salts in sulphate solutions indicates a lower stability for the monosulphato tetravalent creium ion. The conditions of formation, composition and stability of sulphatocerium complexes in aqeous solutions are reported $[3,4]$. Electrophoresis has been used to determine the cornposition of the complex ions and their charges. The instability constants of the corresponding complexes can be calculated from the results of spectrophotometric measurments .

* : Egyptian Armed Forces.

** : Hot Laboratory, Atomic Energy Authority, Cairo, Egypt.

*** : Hot Laboratory, Atomic Energy Authority, Cairo, Egypt. 


\section{EXPE:RIMENTAL :}

All the reagents used were of analytical grade. Cerium sulphate and trivalent cerium perchlorate were prepared from cerium ammonium nitrate as described [6,7] Tetravalent Cerium perchlorate was prepared by electrolytic oxidation of trivalent cerium perchlorate using an two platinum electrodes with voltage difference of 10-12 volts $(=2.48)$ ard electric current of $2.5 \mathrm{~A}$ for $4 \mathrm{~h}[8]$. The degree of oxidation was $89 \%$ alter their quantitative determination spectrophotometrically. In the electrolysis a potentiometric arrangement was applied which allows the voltage for the limiting currerit to be increased. An increase in the electric current is undesirable because it heats the solution. The electrolysis was carried out at $2.0-2.5 \mathrm{~A}$ and $10-12 \mathrm{~V}$ for $45 \mathrm{~min}$. At the end of the experiment the cerium content in the catholyte and the anolyte were determined volumetrically by titrating with a solution of Mohr's salt using phenylanthranilic acid. The results are given in Tables 1 and 2 .

\section{RESULTS AND DISCUSSION :}

In studying equilibrium in sulphuric acid solutions the measurements are made at $\lambda=$ $315 \mathrm{~nm}$ because at this wavelength the absorption by sulphuric and perchloric acids can be neglected as shown in Fig.1. Fig. 2 shows resultsobtained by the isomolar series method with different total concentrations of the reacting components. As the total concentration of reacting components is increased, the maximum absorbance is displàced.

At concentrations $[\mathrm{CelV}]+\left[\mathrm{SO}_{4}\right]^{2-}=0.002 \mathrm{M}$, the $\left[\mathrm{Ce} \mathrm{SO}_{4}\right]^{2+}$ cation is dominant With [CelV $]+\left[\mathrm{SO}_{4}\right]^{2-}=0.005 \mathrm{M}$, mainly $\mathrm{Ce}\left(\mathrm{SO}_{4}\right)_{2}$ is formed. The instability constant of $\left[\mathrm{CeSO}_{4}\right]^{2+}$ icn, calculated from the isomolar series results, is $1.3 \times 10^{-3}$. A study of displacement from the equilibrium when the concentration of one of the components is kept constant while the other varies to allow to determine the composition of the complex and its stability with high accuracy .

Results from measurments on tow series of solutions are shown in Fig. 3 . With a constant sulphat ion concentration and varying tetravalent cerium concentration. Results showed that the $\left[\mathrm{CeSO}_{4}\right]^{2+}$ is formed at concentration ratio greater than 2, but is considerably dissociated as indicated by the absence of a sharp inflection on the curve for variation of absorption with component concentration ratio. Table 3 gives the results of calculating the approximate instability constant of the $\left[\mathrm{Ce} \mathrm{SO}_{4}\right]^{2+}$ complex from the formula:

$$
K=\frac{C_{1} C_{2}(P-1)}{C_{2}-C_{1}(P)}
$$


where: $\mathrm{C} 1$ and $\mathrm{C} 2$ are the ligand concentration for tow expereriments corresponding to which the abso pance are $\mathrm{A} 1, \mathrm{~A} 2$ and $\mathrm{P}=\mathrm{A} 2-\mathrm{A} 1$.

Results from measurments on tow series of solutions are shown in Fig. 4 with constant cerium concentration and varying sulphate concentration. The results indicated that the cerium is completely combined in a complex only when there is a considerable excess of sulphate ions in solution. The number of coordinate $\left(\mathrm{SO}_{4}\right)^{2-}$ group from the results of our experiments coincides with the published data and also the neutral complex $\mathrm{Ce}\left(\mathrm{SO}_{4}\right)_{2}$ is formed under the same conditions. The calculated values of its instability constants are given in Table 4. For both series the ionic strencth of solution was measured and kept

\section{REFERENCES:}

1- T.W.Newton and G.M. Arcand ; J. Amer. chem. Soc., 75, 2449 (1963)

2- R. E. Connick and S.W. Mayers ; J. Amer. Chem. Soc. 73, 167 (1970)

3- R.E.Moore and R.C. Anderson; J. Amer. Chem. Soc.,67, 167 (1965).

4- T.J.Hardwick and Robertson; Canad. J.Chem. ,29, 828 (1961).

5- V.A.Korobovia, G.R. Prik; Russ. J.Inorg. Chem., 10,(4) (1965) .

6- M.E.Hafez , H.M. Rowshdy, N.Hafez ; J.Radioanal. Chem. 45, 277 (1980)

7-M.E.Hafez, N.Hafez ; J.Radioanal. Nucl. Chem. letters. ,166, (3) 203-216 (1992).

8- S.Prakash, G.D.Tuli, S.K.Basu, R.D.Madan, Advanced Inorganic Chemistry , S.Chand \& Company Ltd. , Ram Nagar, New Delhi , (1987). 
Table 3 . Instability constant of the $\left[\mathrm{CeSO}_{4}\right]^{2+}$

\begin{tabular}{|c|c|c|c|c|c|}
\hline $\mathbf{C 1}$ & $\mathbf{C 2}$ & $\mathbf{A 1}$ & $\mathbf{A 2}$ & $\mathbf{P}$ & $\mathbf{K}$ \\
\hline $0.38 \times 10^{2}$ & $1.76 \times 10^{-2}$ & 0.114 & 0.187 & 1.64 & $3.1 \times 10^{-2}$ \\
\hline $1.73 \times 10^{-2}$ & $2.64 \times 10^{-2}$ & 0.187 & 0.232 & 1.24 & $2.4 \times 10^{-3}$ \\
\hline $2.64 \times 10^{-2}$ & $3.52 \times 10^{-2}$ & 0.232 & 0.270 & 1.16 & $8.2 \times 10^{-3}$ \\
\hline $8.52 \times 10^{-2}$ & $4.40 \times 10^{-2}$ & 0.270 & 0.290 & 1.07 & $5.7 \times 10^{-2}$ \\
\hline
\end{tabular}

Table 4. Instability constants of the $\mathrm{CeSO}_{4}$ complex

\begin{tabular}{|c|c|c|c|c|c|}
\hline C1[M] & C2[M] & A1 & A2 & P & K \\
\hline $5 \times 10-2$ & $1 \times 10^{-2}$ & 0.267 & 0.377 & 1.41 & $6.9 \times 10^{-2}$ \\
\hline $1 \times 10-2$ & $2 \times 10^{-2}$ & 0.377 & 0.466 & 1.23 & $5.9 \times 10^{-2}$ \\
\hline $2 \times 10-2$ & $3 \times 10^{-2}$ & 0.466 & 0.494 & 1.07 & $4.8 \times 10^{-2}$ \\
\hline
\end{tabular}


Proceeding of the $\mathbf{1}^{\text {st }}$ ICEENG conference, 24-26 March, 1998.

$E \mathrm{CH}_{2} 2569$

Table 1: Migration of cerium ions in sulphate solutions

\begin{tabular}{|c|c|c|c|c|}
\hline \multirow[t]{2}{*}{ no. } & \multirow[t]{2}{*}{$\begin{array}{c}\text { serium salt } \\
\text { concentration } \\
{[\mathrm{M}]}\end{array}$} & \multirow{2}{*}{$\begin{array}{l}\text { concentration of } \\
\mathrm{H}_{2} \mathrm{SO}_{4} \\
{[\mathrm{M}]}\end{array}$} & \multicolumn{2}{|c|}{$\begin{array}{c}\text { mohr's salt solution } \\
{[\mathrm{ml}]}\end{array}$} \\
\hline & & & catholyte & anolyte \\
\hline 1 & 0.025 & 0.3 & 0.4 & 2.09 \\
\hline 2 & 0.025 & 0.5 & 0.2 & 4.30 \\
\hline 3 & 0.025 & 1.0 & 0.3 & 3.70 \\
\hline 4 & 0.025 & 2.0 & 0.8 & 4.10 \\
\hline 5 & 0.025 & 4.0 & 0.2 & 4.30 \\
\hline 6 & 0.025 & 6.0 & 0.5 & 3.80 \\
\hline 7 & 0.025 & 8.0 & 0.3 & 3.50 \\
\hline 8 & 0.0125 & 2.0 & 0.6 & 4.40 \\
\hline 9 & 0.0125 & 4.0 & 0.4 & 4.30 \\
\hline 10 & 0.0125 & 6.0 & 0.8 & 4.50 \\
\hline 11 & 0.0030 & 1.0 & 0.2 & 2.50 \\
\hline 12 & 0.0030 & 2.0 & 0.7 & 2.80 \\
\hline 13 & 0.0030 & 4.0 & 0.9 & 3.20 \\
\hline
\end{tabular}

Table 2: Migration of cerium ions in perchlorate solutions in the presence of $\mathrm{Na}_{2} \mathrm{SO}_{4}$

\begin{tabular}{|c|c|c|c|c|}
\hline EXF'. & $\begin{array}{c}\text { concentration of } \\
\text { serium salt }\end{array}$ & $\mathrm{Na}_{2} \mathrm{SO}_{4}$ concentration & \multicolumn{2}{|c|}{ mohr's salt [ml] } \\
\cline { 3 - 4 } & & & catholyte & anolyte \\
\hline 1 & $1.02 \times 10^{-2}$ & $0.98 \times 10^{-2}$ & 2.10 & 0.80 \\
\hline 2 & $2.00 \times 10^{-3}$ & $3.00 \times 10^{-3}$ & 2.80 & 2.20 \\
\hline 3 & $1.089 \times 10^{-2}$ & $3.23 \times 10^{-2}$ & 2.3 & 2.10 \\
\hline
\end{tabular}




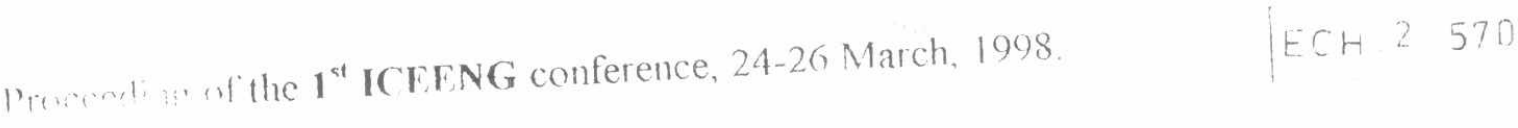

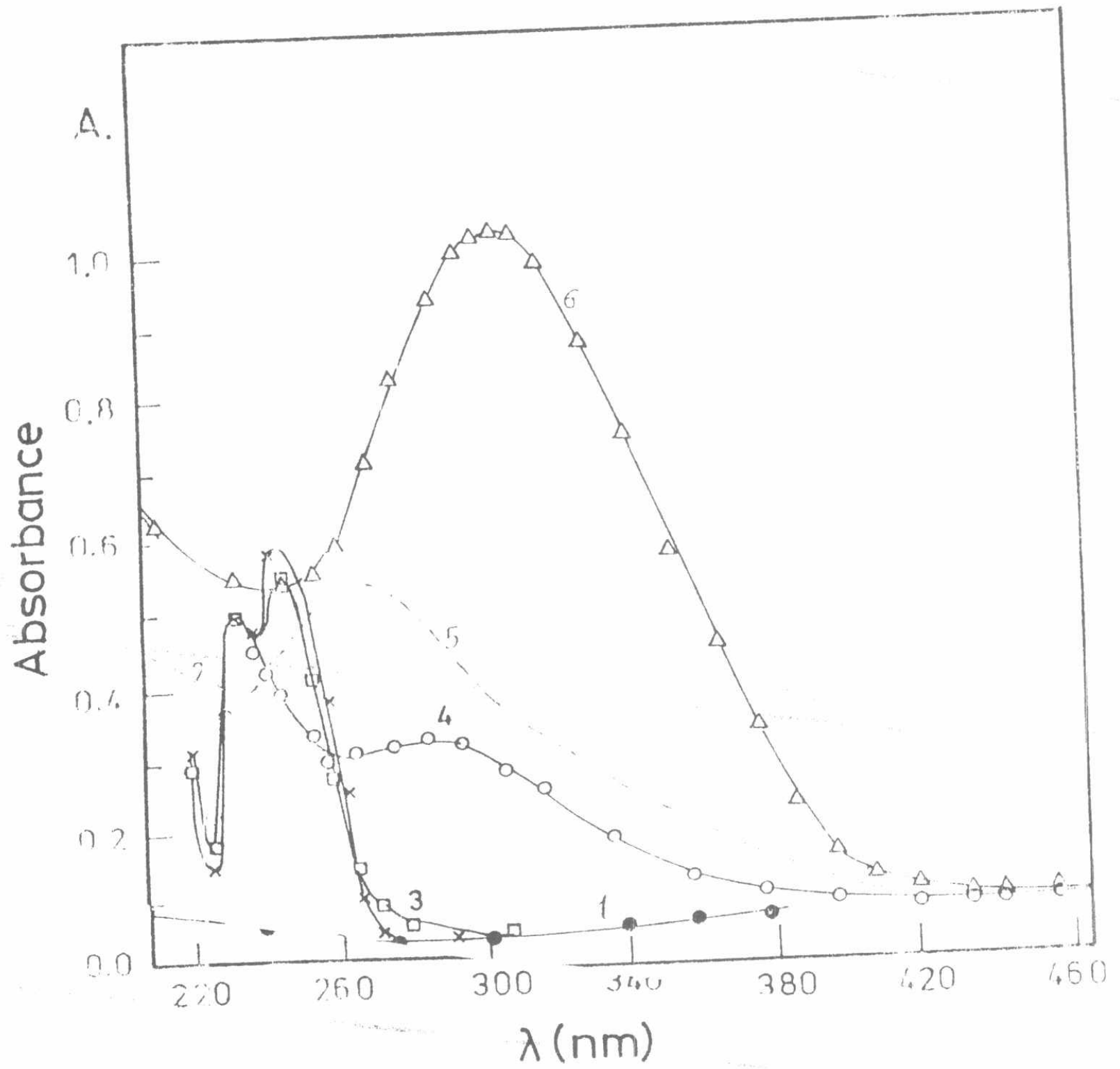

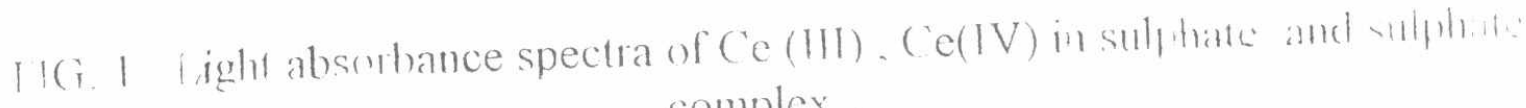
complex.

- (1) 11,53$)_{4} 1 \mathrm{~N}$

(?) $\mathrm{Ce}\left(\mathrm{ClO}_{4}\right)_{3}$ in $1 \mathrm{~N} \mathrm{HClO}_{4}$

1 13) Ce, (1) 1:

() 1) $\mathrm{Ce}(\mathrm{SO})_{1}$ : in $1 \mathrm{NH}_{2} \mathrm{SO}_{4}$

$15)$ ( e SO,

(16) $\left(\therefore, \mathrm{S}()_{1}\right)$, in $1 \mathrm{~N} \mathrm{H}_{2} \mathrm{SO}_{4}$ 


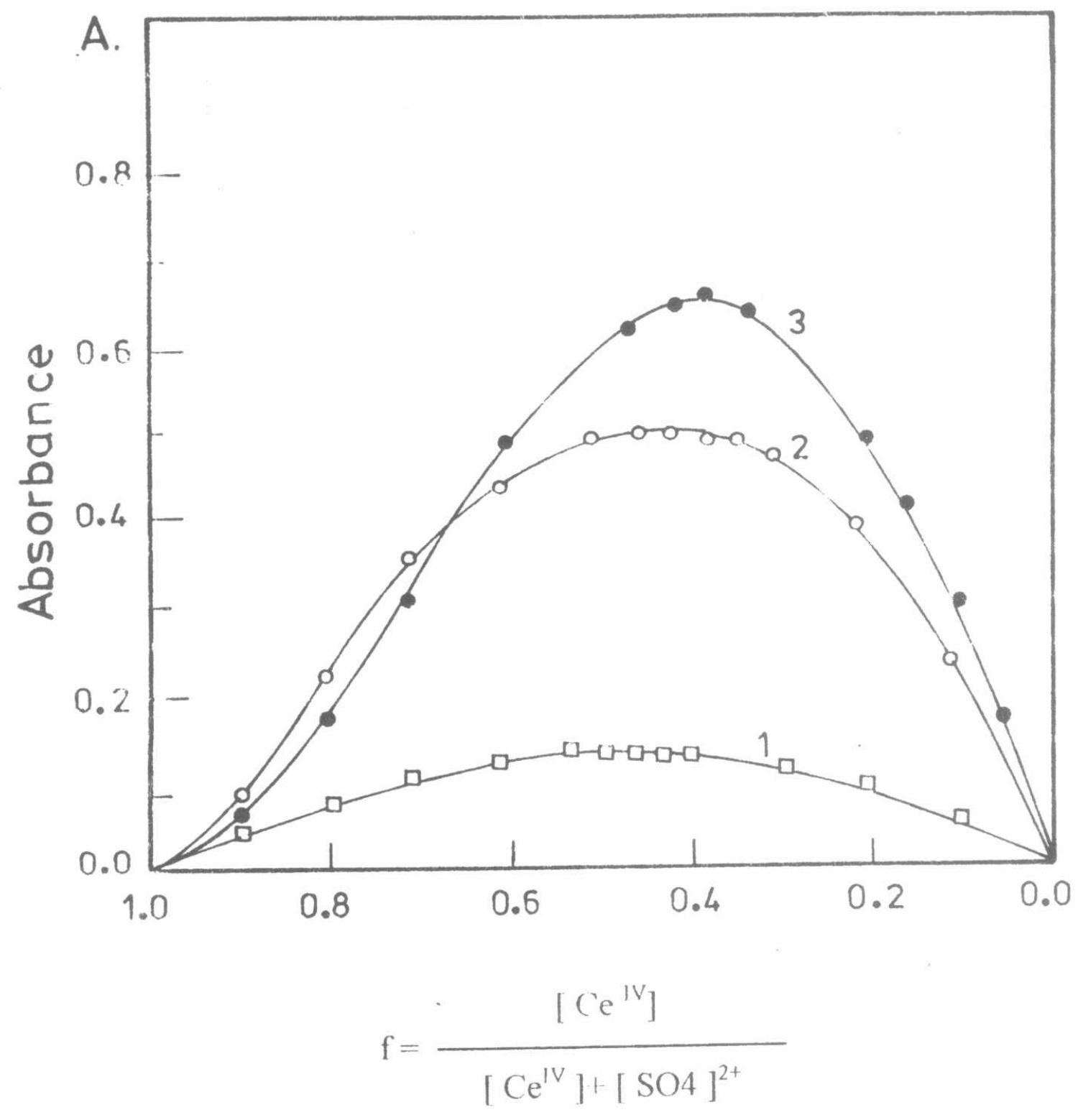

[iTC. 2 I.othermal series

$\square \quad[\mathrm{CelV}]+\left[\mathrm{SO}_{4}{ }^{2-}\right]=0.002 \mathrm{M} \quad \lambda 315 \mathrm{~nm}$.

- $\left[\mathrm{CeIV} !+\left[\mathrm{SO}_{4}{ }^{2-}\right]=0.005 \mathrm{M} \quad \lambda 315 \mathrm{~nm}\right.$..

- $|\mathrm{CelV}|+\left[\mathrm{SO}_{4}{ }^{2-j}-0.051 \mathrm{M} \lambda 315 \mathrm{~mm}\right.$. 


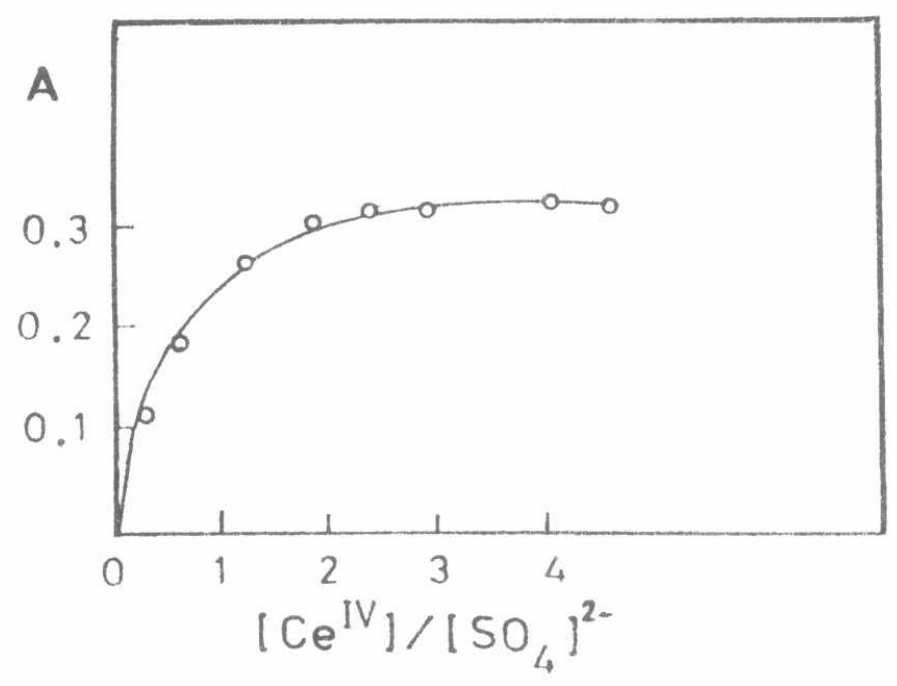

Fis i 3: Chang in the absorbance $[\mathrm{A}]$ of the solution with constant sulphate ins concentration and varying CelV ion concentration. $\lambda-315 \mathrm{~mm},|\mathrm{SO} 4|^{2-}=0.003 \mathrm{~g}$ ion $/$ lit .

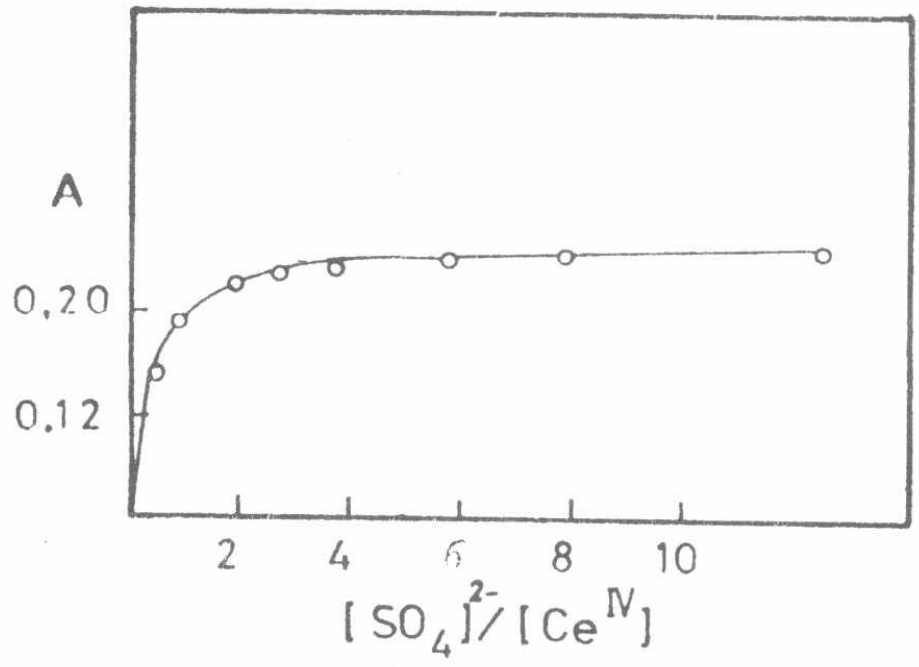

FIC 4: (hang in the absorbace [A] of the solution with constant $\mathrm{Ce}$ (IV) ion concetration and varying sulphate ion concentrations. [( $\mathrm{e}$ [ IV $)$ - $0.001 \mathrm{~g}$ inn! lit , $\lambda=315 \mathrm{~mm}$ 